\title{
Utilisation of quality antenatal, delivery and postnatal care services in Nepal: An analysis of Service Provision Assessment
}

\author{
Resham B. Khatri ${ }^{1,2^{*}}$ D, Jo Durham ${ }^{1,3}$ and Yibeltal Assefa ${ }^{1}$
}

\begin{abstract}
Background: Nepal has improved access and utilisation of routine maternal and newborn health (MNH) services. Despite improved access to routine MNH services such as antenatal care (ANC), and delivery and postnatal care (PNC) services, the burden of maternal and neonatal deaths in Nepal remains high. Most of those deaths could be prevented by improving utilisation of evidence-informed clinical MNH interventions. However, little is known on determinants of utilisation of such clinical MNH interventions in health facilities (HFs). This study investigated the determinants of utilisation of technical quality MNH services in Nepal.

Methods: This study used data from the 2015 Nepal Services Provision Assessment. A total of 523 pregnant and 309 postpartum women were included for the analysis of utilisation of technical quality of ANC, and delivery and PNC services, respectively. Outcome variables were utilisation of better quality i) ANC services, and ii) delivery and PNC services while independent variables included features of HFs and health workers, and demographic characteristics of pregnant and postpartum women. Binomial logistic regression was conducted to identify the determinants associated with utilisation of quality $\mathrm{MNH}$ services. The odds ratio with $95 \%$ confidence interval (Cls) were reported at the significance level of $p<0.05$ (two-tailed).
\end{abstract}

Results: Women utilised quality ANC services if they attended facilities with better HF capacity $(a \mathrm{OR}=2.12 ; 95 \% \mathrm{Cl}$ : $1.03,4.35)$. Women utilised better quality delivery and PNC services from private HFs compared to public HFs $(\mathrm{aOR}=2.63 ; 95 \% \mathrm{Cl}: 1.14,6.08)$. Women utilised better technical quality ANC provided by nursing staff compared to physicians (adjusted odds ratio $(\mathrm{aOR})=2.89 ; 95 \% \mathrm{Cl}: 1.33,6.29)$, and from staff supervised by a higher authority compared to those not supervised $(\mathrm{aOR}=1.71 ; 95 \% \mathrm{Cl}: 1.01,2.92)$. However, compared to province one, women utilised poor quality delivery and PNC services from HFs in province two (aOR $=0.15 ; 95 \% \mathrm{Cl}: 0.03,0.63)$.

Conclusions: Women utilised quality MNH services at facilities with better HF capacity, service provided by nursing staff, and attended at supervised HFs/health workers. Provincial and municipal governments require strengthening HF capacities (e.g., supply equipment, medicines, supplies), recruiting trained nurse-midwives, and supervising health workers.

Keywords: Technical quality, Nepal, antenatal care, delivery and postnatal care services, health facility, utilisation

\footnotetext{
* Correspondence: rkchettri@gmail.com

'School of Public Health, Faculty of Medicine, University of Queensland, Brisbane, Australia

${ }^{2}$ Health Social Science and Development Research Institute, Kathmandu, Nepal

Full list of author information is available at the end of the article
}

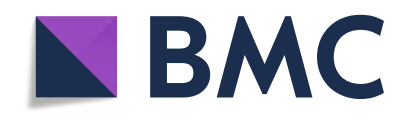

(c) The Author(s). 2021 Open Access This article is licensed under a Creative Commons Attribution 4.0 International License, which permits use, sharing, adaptation, distribution and reproduction in any medium or format, as long as you give appropriate credit to the original author(s) and the source, provide a link to the Creative Commons licence, and indicate if changes were made. The images or other third party material in this article are included in the article's Creative Commons licence, unless indicated otherwise in a credit line to the material. If material is not included in the article's Creative Commons licence and your intended use is not permitted by statutory regulation or exceeds the permitted use, you will need to obtain permission directly from the copyright holder. To view a copy of this licence, visit http://creativecommons.org/licenses/by/4.0/ The Creative Commons Public Domain Dedication waiver (http://creativecommons.org/publicdomain/zero/1.0/) applies to the data made available in this article, unless otherwise stated in a credit line to the data. 


\section{Introduction}

Over the past two decades, Nepal has made significant improvements in accessing routine maternal and newborn health $(\mathrm{MNH})$ services such as antenatal care (ANC), delivery and postnatal care (PNC) services [1]. Evidence indicates improvement is associated with the implementation of the Safe Delivery Incentive Program (SDIP) (called as Aama Program in Nepali) in 2006 in Nepal [2], a nationwide program providing conditional cash transfers to women who deliver at a health facility (HF) assisted by skilled birth attendants (SBAs) and who attend at least four ANC visits and delivery, mostly in public HFs and some private HFs [2, 3]. Nevertheless, reducing the neonatal and maternal mortality ratio (MMR) remains challenging, e.g., from 2006 to 2016, the institutional delivery rate increased from 18 to 59\%, while MMR decreased only from 281 to 259 (reported as per 100,000 live births) in that period [1]. A study in India also showed that improved access to $\mathrm{MNH}$ services has not significantly reduced maternal and neonatal deaths [4]. One explanation for this is that the quality of care that women receive across the $\mathrm{MNH}$ continuum of care $(\mathrm{CoC})$ is poor and therefore is having a limited effect on mortality.

The quality of health care is multifaceted, and its measurement is complex. According to the Donabedian's model of health care, quality of health care is comprised of three components: input (or structural quality), process, and outcome [5]. Structural or input quality (HF capacity) or health system readiness is the precondition for better quality technical/clinical care. Process of care is the delivery of health services, and it is often seen as consist of two components: technical quality, and social, or perceived quality [6]. Outcome quality is an effect of health care and is generally measured in terms of improved health status or reduced morbidities or mortalities. Thus, the measurement of health care quality is the assessment of health system quality, and considers overall health system inputs, delivery and utilisation of care, and effects of health care, including client satisfaction and respectful and dignified care $[7,8]$. Health system quality means better health system readiness, delivery and utilisation of quality health services by those who need them [7].

The clinical or technical quality of $\mathrm{MNH}$ services is measured by the delivery of sets of clinical interventions and procedures during services delivery by trained health providers or received by health service users $[9,10]$. The health care utilisation (probability receiving health interventions from the available providers at HFs) incorporates access to health services (reaching the care) as well as care provided in the HFs by providers (provision of care) [11]. The utilisation of better technical quality of $\mathrm{MNH}$ services by mothers and newborns can have a real effect on the reduction of maternal and neonatal morbidities and mortalities $[9,12]$. In addition to technical quality, the client's perception of quality is important and is dependent on the sociocultural context and individual perceptions [13]. However, perceived quality can also be affected by the social desirability bias (reporting better/positive behaviours from fear of not being bad) [14].

Studies conducted in Nepal have mainly focused on uptake of specific MNH interventions from household survey data [15-17] while further analysis of facility survey data have mainly looked at access to health services [18] or HF capacity (structural quality) or health system readiness $[19,20]$ or perceived quality of $\mathrm{MNH}$ care $[13,21]$. A study by Karkee and colleagues reported that public hospitals and peripheral HFs were rated lowest if HFs had inadequate medical equipment and room, lack of privacy, inadequacy of health staff trained on women's health, lack of provision of adequate water supply, clean environment and privacy [22]. In another study, women perceived better quality of care in private HFs [23]. The same study reported women also bypassed peripheral HFs, preferring to attend referral hospitals for perceived better quality maternity care. A study by Khatri and colleagues revealed women preferred home delivery without skilled providers due to poor perceived quality of care at local HFs [24]. Other research also indicated HFs in province two demonstrated poor health system readiness for non-communicable diseases (NCDs) compared to province one [25], and inadequately staffed HFs for the delivery of MNH services [26].

Studies in Nepal, however, are lacking on the determinants of utilisation of better clinical/technical quality MNH services at HFs. Current routine health information system lacks data to measure the quality of $\mathrm{MNH}$ care and track the determinants of utilisation by pregnant and postpartum women. The 2015 Nepal Service Provision Survey (SPA) collected information on utilisation of health service using HF inventory, observation of interactions of health services providers and clients, and client exit interviews of health services users on the day of the HF survey. The HF inventory is the process of collecting information on the availability of equipment, medicines, health workforce and availability of protocols/guidelines of services, observation and review of records, and interviews with those in-charge of HFs. Further analysis of the data of SPA 2015 could provide potential indicators to track policy implementation and patterns of utilisation of quality $\mathrm{MNH}$ services. Therefore, this study aimed to examine the determinants of utilisation of better technical quality $\mathrm{MNH}$ services in Nepal. The study's findings can inform decision-makers in the revision of programmes and strategies for 
achieving universal coverage of quality $\mathrm{MNH}$ services and Sustainable Development Goal three (SDG3).

\section{Nepal's health system and policy context for MNH}

Nepal has a three-tier federal health system in line with the governance system: federal, provincial, and local governments (municipal governments) (Fig. 1). The current health system has decentralised the resources and authority to provincial and local/municipal governments [30]. The federal republic constitution of Nepal (2015) recognises basic health services as fundamental rights, and available through public funding [31].

The health care delivery system is mixed with private providers dominant in tertiary and secondary health care services and concentrated in urban areas in Nepal [32]. Province three, including the federal capital (Kathmandu), has the highest private HFs [33]. The public health system provides basic health services and secondary health care services in urban, rural and regional areas through public funding. People require to pay health care beyond basic health services in both public and private HFs [34]. The proportion of out of pocket (OOP) expenditure is high (57\% of current health expenditure) [35]. In private HFs, people must pay for basic health services, including routine $\mathrm{MNH}$ services [33]. The cost of care of those services is low in public facilities but expensive in private HFs. Since 2016, Nepal has implemented the National Health Insurance Program (NHIP), primarily focusing on point of care public facilities and referral to contracted private HFs; however, private HFs have very limited participation in the program, low enrollment rate and high dropout rate in the renewal of premium further challenge the implementation of the NHIP [36].

Under the publicly funded National Safe Motherhood Program, MNH services are delivered up to the local level HFs free of cost [27]. Institutional delivery service is available from the health post level with skilled birth attendants (such health posts are also called birthing centers) to tertiary level facilities. Two important policy shifts in 2005 were the Skilled Birth Attendant (SBA) policy and the Safe Delivery Incentive Policy (SDIP) [37]. The SBA policy shifted the task of childbirth services to SBAs (e.g., auxiliary nurse midwives with two-months long in-service midwifery training) at the birthing center level, while to address the demand side financial barriers, the SDIP provisions a minimal monetary incentive $(\approx 10$ USD) for women who complete $4 \mathrm{ANC}$ visits and gave

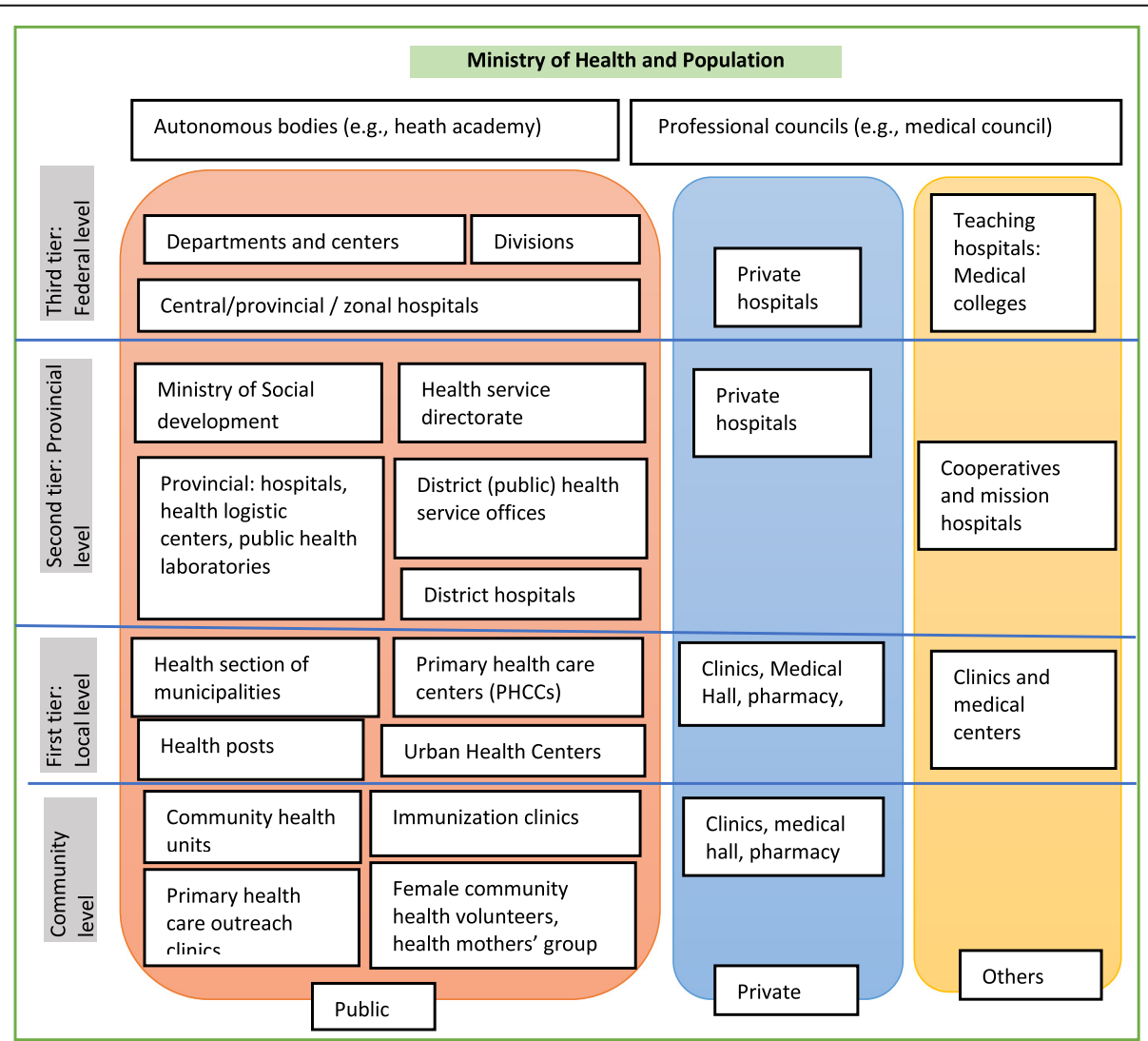

Fig. 1 Schematic diagram of health system organogram of Nepal. Source: Prepared by the first author (RBK) based on information from the Department of Health Services (dohs.gov.np); Annual Health Report 2018 [27], and previous studies [28, 29] 
birth in accredited HFs [38]. The SDIP or "Aama" program is implemented in most public facilities and a limited number of private HFs [32]. More recent policies [39-41] and the Nepal Health Sector Strategy (NHSS) 2016-2021 [42] have focused not only on demand but also improved quality $\mathrm{MNH}$ services and to contribute to the SDG3 $[41,43]$. Nepal's Road to Safe Motherhood Plan 2030 [44] also emphasises universal coverage of quality MNH services to achieve the SDG3 [45].

\section{Methods}

\section{Study context}

Nepal is ethnolinguistically diverse country with a population of 29 million, residing125 different caste/ethnic groups who speak 123 languages (Nepali is the official language) [37]. Life expectancy is 70.8 years (male: 69.3 and female: 72.2$), 60 \%$ are living in urban areas [46]. More than one in three (34\%) people live below the poverty level based on the multidimensional poverty index [47]. Additionally, two-thirds of Nepal's gross national product (GNP: USD 30.64B) is from agricultural sector (37\%) and remittance from foreign employment (32\%) [48].

As presented above, the health system has three tiers, and service delivery is provided by a mix of public and private HFs. There are 6.7 health workers per 10,000 populations, which is significantly less than the World Health Organization (WHO) standards (23/10,000 population) [34]. Of the seven provinces in Nepal (Fig. 2), province six is the most remote province where HFs are scattered and often difficult to reach, especially those in more rural/remote areas of the province. Compared to other provinces, province two is geographically accessible, but has low socioeconomic indicators and the highest number of childbirths annually [32].

\section{Study design}

This was a cross-sectional study based on further analysis of the data derived from the 2015 Nepal SPA (also called as the 2015 Nepal Health Facility Survey) [29]. The 2015 Nepal SPA was a cross-sectional study representative of the main types of HFs in Nepal, was based on generic designs with modules developed by the Measure DHS, ICF Macro. The SPA tools were revised and modified to Nepal's context and aligned with WHO's Service Availability and Readiness Assessment (SARA) [49].

\section{Sampling design and data collection}

In the 2015 Nepal SPA, data were collected using the Donabedian model of quality of health care measurement (inputs-process-outcome) [29]. Inputs related information were collected items derived from the SARA Manual [49]. All input related information were collected using the HF inventory (process of collecting information through observations of stores, reviewing records, and interactions with the most knowledgeable person in HFs, usually HF in charge) (questionnaire pages 225-332 of the 2015

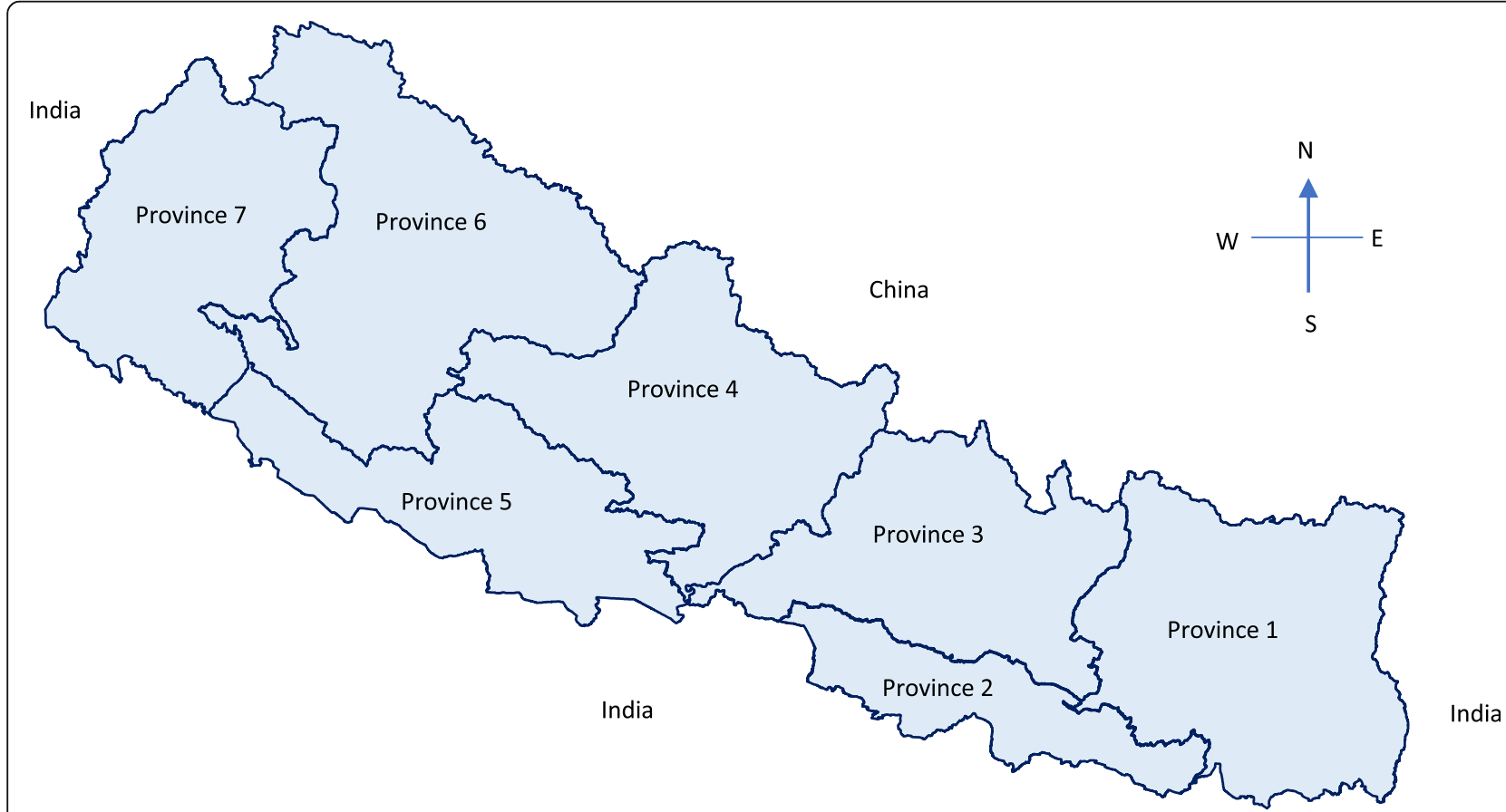

Fig. 2 The provincial map of Nepal. Source: Map is prepared in word processer document. The shape files were obtained from the Government of Nepal, Ministry of Federal Affairs and Local Development and were publicly available for unrestricted use (https://data.humdata.org/dataset/admin-shapefiles-of-nepal-mofald) 
Nepal SPA original report) [29]. Information on different services specific processes of care (utilisation of services) and outcome (e.g., client satisfaction) were collected by observation of interactions of health services and clients and exit interview on the day of HF survey (questionnaire pages 333-415 of the original report) [29].

The 2015 Nepal SPA was a two-stage cluster survey where $992 \mathrm{HFs}(963 \mathrm{HFs}$ when weighted) were selected randomly from the master list of 4719 (HFs proportionate representation of three regions and types of HFs). In addition, interviews with health workers were conducted. In total, the survey included 523 pregnant women who received the first ANC visit (minimum one to maximum four pregnant women per HF, selected from $269 \mathrm{HFs}$ ) and 309 (minimum one to four postpartum women per HF, selected from $109 \mathrm{HFs}$ ) postpartum women who received delivery and PNC services at the HFs on the day of the survey were included in the analysis. In the current study, multiple sources of data were used: HF inventory, observation of health services delivery, and client exit interviews with pregnant women who attended for first ANC visit, and postpartum mothers who discharged on the day of survey. Multiple data files (HF inventory, interview with health workers, observation of interactions of womenproviders, and client exit interviews) for each outcome variable were merged into one file using a unique identifier (HF number) available in the data file. The unit of analysis was pregnant women for ANC services, and postpartum women for delivery and PNC services.

\section{Conceptual framework of the study}

Based on the review of previous conceptual frameworks [50-52], including WHO's SDH framework [52], a conceptual framework was developed (Fig. 3).
The conceptual framework included inputs that consisted of several determinants, their contexts and mechanisms which may act at different levels (system, organisation and individual) [53]. These contexts and mechanisms produce the outputs of utilisation of quality $\mathrm{MNH}$ services. Utilisation of better quality $\mathrm{MNH}$ services leads to the survival of mothers and newborns, economic benefit, and confidence in the system [7]. Inputs include determinants into structural, intermediary and health system domains. The structural domain covers all basic sociopolitical system and organisational factors and individual structural determinants(e.g., governance, wealth status, ethnicity, gender) [52]. The intermediary domain covers non-health sector underlying factors that affect the conditions of health via influencing the family/community contexts (living and working conditions), and characteristics of individuals such as biological, behavioural and psychological determinants [54]. Structural factors influence the non-health sector system and organisational factors, and characteristics of individuals. The health system domain includes several variables that can influence the provision and delivery of quality health services, including MNH services [55]. Determinants of structural and intermediary domains influence the systems, organisational and characteristics of health services users of health system domain.

\section{Study variables}

In this study, the unit of the analysis was health service users (pregnant women and postpartum women). Based on the information available in the 2015 Nepal SPA, independent variables included characteristics of women, characteristics of health workers from where they received MNH services, and the HFs women attended (See
Inputs: Determinants, systems, institutions, individuals, contexts, and mechanisms

\begin{tabular}{|l|}
\hline $\begin{array}{l}\text { Structural domain: } \\
\text { Governance; macroeconomic } \\
\text { and social policies; culture and } \\
\text { societal values; individuals' } \\
\text { characteristics (e.g., social class; } \\
\text { gender; education, occupation; } \\
\text { income; religion, ethnicity); } \\
\text { management authority of HFs }\end{array}$ \\
\hline \\
\hline $\begin{array}{l}\text { Intermediary domain: Sectors } \\
\text { that influence conditions of } \\
\text { health; daily lives; } \\
\text { transportation, locations of HFs } \\
\text { individuals' behavioural; } \\
\text { biological and psychological } \\
\text { characteristics }\end{array}$ \\
\hline
\end{tabular}

Structural domain

Governance; macroeconomic societal values; individuals' characteristics (e.g., social class; income; religion, ethnicity); management authority of HFs Health policies; competent and motivated human systems; services of health services

\section{Outputs}

Outcomes

Health system domain: medicines, equipment health infrastructure, resources; information delivery; individuals' experiences on uptake

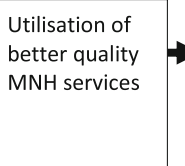

Reduced morbidities and mortalities. Economic benefits. Competent system and confidence in the system

Fig. 3 A conceptual framework to guide the analysis of this study 
details in supplementary file Table S1). Based on previous literature $[52,53]$, these variables were grouped into three domains as guided by the conceptual framework (Fig. 3). Structural variables included women's ethnicity, the managing authority of HFs (public, private), and the education level of women. Intermediary variables included province, region, age of women, facility type, companion at HFs (usually, husband, mother-in-law), and waiting time. Health system variables included HF capacity, types of HWs, mode of delivery, several health management-related variables (Supplementary file Table S1). The HF capacity (for ANC services, and delivery and PNC services) was also considered an independent variable and calculated using Principal Component Analysis (PCA). The PCA generates composite-scale coefficients that can be used to reduce indicators to indices for application in comparative analyses of service readiness [56]. To calculate the HF capacity, a total of 53 items were taken for ANC services (Supplementary file Table S2), and 73 items were taken for delivery and PNC services (Supplementary file Table S3). All these items were then categorised into yes/no and later converted into dummy variables by assigning the value of 1 to 'Yes' and 0 to 'No'. Taking an arbitrary cut-off point of HF index based on previous studies [57, 58], HF capacity was categorised into three groups: low, medium and high.

\section{Outcome measurement}

Two outcomes of this study were utilisation of technical quality, i) ANC services, and ii) delivery and PNC services. The WHO recommends every pregnant woman should receive recommended interventions for healthy pregnancy and childbirth. The guideline of the Nepal Safe Motherhood Program also defines the list of MNH interventions to be taken by every pregnant, postpartum woman and newborn [59]. The 2015 Nepal SPA also collected information on ANC (Supplementary file, Table S4) and delivery and PNC interventions (Supplementary file, Table S5) used to assess the technical/clinical quality of MNH services. All ANC, delivery and postnatal interventions were denoted as yes or no categories, whether they received those interventions or not in the HFs visit. Each item had a dummy value of 'yes' $(=1)$ if items were available on the day of the survey; otherwise, 'no' $(=0)$ (for instance, if iron tablets available in HFs $(=1)$, if not $(=0))$. The PCA procedure was conducted separately to calculate the quality of ANC services, as well as delivery and PNC services. Using PCA procedure, the quality score of each outcome variable was dichotomised. The PCA procedure takes the arbitrary cut-off point to dichotomise the technical quality score $[57,58]$. The utilisation of technical quality of ANC services was categorised: Poor quality $=0$; better quality $=1$. The second outcome variable, i.e., delivery and PNC services was also dichotomised using a similar PCA procedure.

\section{Data analysis}

Descriptive and logistic regression analyses were conducted. Descriptive statistics were reported as frequencies and proportions (\%). Binomial logistic regression analysis was conducted to identify the determinants of utilisation of better technical quality for each outcome variable. First, bivariable logistic regression analysis was conducted to identify the crude estimates of the association of each independent and outcome variable of interest. Before running the multivariable regression models, multicollinearity was checked and excluded independent variables having variation inflation factor $\geq 3$ [60]. In the multivariable analysis, backward stepwise elimination technique was conducted. In each step of the backward elimination logistic regression process, the least significant variable at each step (which has the highest $p$-value in the model) was excluded and repeated the regression analysis. This process was repeated until the stopping rule was satisfied when all remaining variables in the model have a $\mathrm{p}$-value smaller than pre-specified threshold $(p<0.20)[61,62]$. In the final regression model, the statistical significance level was $p<0.05$ (two-tailed). Again, to confirm the final regression model, we run the backward stepwise elimination logistic regression model a) entering only potential risk factors with $p<0.20 \mathrm{ob}$ tained in the bivariate analysis for backward elimination process, and b) testing the backward elimination method by including all potential risk factors. The goodness of fit test was conducted using the Hosmer Lemeshow test (non-significant results at $p>0.05$ indicated an adequate fit). Regression analyses outputs were reported as the Odds Ratios (ORs) with 95\% confidence intervals (CIs). The clustering effect was adjusted using sampling design in the data analysis stage using the clients' weight and accounting for survey strata: region and types of HFs. All analyses were conducted using the "svy" command function and considering the clustering effect in Stata 14.0 (Stata Corp, 2015).

\section{Results \\ Descriptive characteristics of women (pregnant and postpartum)}

Table 1 shows the descriptive characteristics of women who attended HFs for the first ANC visit, and women who delivered at HFs and discharged on the day of the facility survey. Among the 523 pregnant women who made the first ANC visit, three in five (58\%) received services from primary health care centres (PHCCs) and hospital HFs. The majority (86\%) of pregnant women received ANC services from publicly managed HFs. More than two in five (44\%) pregnant women were aged 20- 
Table 1 Descriptive characteristics of women who received routine MNH (ANC visit, and delivery and PNC services) services, Nepal SPA 2015

\begin{tabular}{|c|c|c|c|c|c|c|c|}
\hline \multicolumn{4}{|c|}{ Pregnant women attended HFs for their first ANC visit $(N=523)$} & \multicolumn{4}{|c|}{ Postpartum women discharged from HFs $(N=309)$} \\
\hline Determinants & Categories & Frequency & $\%$ & Determinants & Categories & Frequency & $\%$ \\
\hline Structural & & & & Structural & & & \\
\hline \multirow[t]{5}{*}{ Ethnicity (women) } & Brahmin and Chhetri & 102 & 19.6 & Ethnicity (women) & Brahmin and Chhetri & 155 & 50.2 \\
\hline & Janajatis & 155 & 29.5 & & Janajatis & 66 & 21.3 \\
\hline & Madhesi & 157 & 30.0 & & Madhesi & 51 & 16.7 \\
\hline & Dalit & 66 & 12.6 & & Dalit & 37 & 11.8 \\
\hline & Muslims and others & 43 & 8.3 & Managed by & Private & 97 & 31.3 \\
\hline \multirow[t]{3}{*}{ Education (women) } & Never been school & 155 & 29.6 & & Public & 212 & 68.7 \\
\hline & $<10$ years & 216 & 41.4 & Intermediary & & & \\
\hline & SLC and above & 152 & 29.0 & Province & One & 24 & 7.9 \\
\hline \multirow[t]{2}{*}{ Managed by } & Private & 73 & 14.0 & & Two & 46 & 14.8 \\
\hline & Public & 450 & 86.0 & & Three & 110 & 35.7 \\
\hline Intermediary & & & & & Four & 38 & 12.4 \\
\hline \multirow[t]{7}{*}{ Province } & One & 89 & 16.9 & & Five & 48 & 15.6 \\
\hline & Two & 154 & 29.5 & & Six & 19 & 6.2 \\
\hline & Three & 116 & 22.2 & & Seven & 23 & 7.3 \\
\hline & Four & 25 & 4.8 & Women's age (years) & $15-19$ & 36 & 11.6 \\
\hline & Five & 84 & 16.0 & & $20-24$ & 130 & 42.2 \\
\hline & Six & 20 & 3.9 & & $25-29$ & 96 & 31.1 \\
\hline & Seven & 35 & 6.7 & & 30 and above & 47 & 15.1 \\
\hline \multirow[t]{3}{*}{ Region } & Mountain & 16 & 3.0 & Companion in delivery & No & 93 & 30.2 \\
\hline & Hill & 172 & 32.9 & & Yes & 216 & 69.8 \\
\hline & Terai & 335 & 64.1 & Health system & & & \\
\hline \multirow[t]{4}{*}{ Women's age (years) } & $15-19$ & 120 & 23.0 & HF capacity & Low & 123 & 39.8 \\
\hline & $20-24$ & 230 & 43.9 & & Medium & 105 & 34.0 \\
\hline & $25-29$ & 118 & 22.6 & & High & 81 & 26.1 \\
\hline & 30 and above & 55 & 10.5 & Supervision of staff & No & 119 & 38.5 \\
\hline \multirow[t]{3}{*}{ Waiting time } & Immediately & 149 & 28.4 & & Yes & 190 & 61.5 \\
\hline & Up to $30 \mathrm{~min}$ & 251 & 48.0 & Feedback collection & Yes & 249 & 80.6 \\
\hline & $>30 \min$ & 123 & 23.5 & & No & 60 & 19.4 \\
\hline \multirow[t]{2}{*}{ Facility types } & PHCCs and above & 303 & 57.9 & QA activities & No & 214 & 69.3 \\
\hline & HPs and clinics & 220 & 42.1 & & Yes & 95 & 30.7 \\
\hline Health system & & & & Timely decision & No & 25 & 8.0 \\
\hline \multirow[t]{3}{*}{ HF capacity } & Low & 175 & 33.5 & & Yes & 284 & 92.0 \\
\hline & Medium & 174 & 33.3 & Providers & Nurse and other & 203 & 65.8 \\
\hline & High & 174 & 33.3 & & Doctor & 106 & 34.2 \\
\hline \multirow[t]{2}{*}{ Supervision of staff } & No & 172 & 33.0 & PNC mothers & Nurse and others & 137 & 44.5 \\
\hline & Yes & 351 & 67.0 & & Doctor & 172 & 55.5 \\
\hline \multirow[t]{3}{*}{ HF meeting } & No & 64 & 12.3 & PNC newborns & Nurse and others & 134 & 43.2 \\
\hline & Sometimes & 81 & 15.5 & & Doctor & 175 & 56.8 \\
\hline & Monthly & 378 & 72.3 & First baby & No & 136 & 44.1 \\
\hline \multirow[t]{2}{*}{ Feedback collection } & Yes & 326 & 62.4 & & Yes & 173 & 55.9 \\
\hline & No & 197 & 37.6 & Delivery & Normal & 239 & 77.4 \\
\hline
\end{tabular}


Table 1 Descriptive characteristics of women who received routine MNH (ANC visit, and delivery and PNC services) services, Nepal SPA 2015 (Continued)

\begin{tabular}{|c|c|c|c|c|c|c|c|}
\hline \multicolumn{4}{|c|}{ Pregnant women attended HFs for their first ANC visit $(N=523)$} & \multicolumn{4}{|c|}{ Postpartum women discharged from HFs $(N=309)$} \\
\hline \multirow[t]{2}{*}{ QA activities } & No & 392 & 74.9 & & Assisted & 70 & 22.6 \\
\hline & Yes & 131 & 25.1 & Aama program & No & 78 & 25.1 \\
\hline \multirow[t]{2}{*}{ Availability of waiting area } & No & 39 & 7.4 & & Yes & 231 & 74.9 \\
\hline & Yes & 484 & 92.6 & & & & \\
\hline \multirow[t]{4}{*}{ Provider category } & GP/Specialists & 77 & 15.2 & & & & \\
\hline & MBBS & 23 & 4.5 & & & & \\
\hline & Nursing & 392 & 77.5 & & & & \\
\hline & Paramedics & 14 & 2.8 & & & & \\
\hline \multirow[t]{2}{*}{ Supervision to staff } & No & 265 & 50.5 & & & & \\
\hline & Yes & 258 & 49.5 & & & & \\
\hline \multirow[t]{2}{*}{ Problem felt } & No & 224 & 42.9 & & & & \\
\hline & Yes & 299 & 57.1 & & & & \\
\hline \multirow[t]{2}{*}{ Need to pay } & Yes & 168 & 32.1 & & & & \\
\hline & No & 355 & 67.9 & & & & \\
\hline
\end{tabular}

24 years, and nearly one-third (30\%) of pregnant women had never been to school. Among 309 postpartum women, more than two-thirds (69\%) received delivery and PNC services from public facilities. Half (50\%) were from privileged (Brahmin/ Chhetri) ethnic groups. Onethird (34\%) of women were from province three. Nearly four in five women $(77 \%)$ had normal deliveries. Twothirds of women (66\%) utilised delivery and PNC services from midwives and nurses.

\section{Determinants of utilisation of better technical quality routine $\mathrm{MNH}$ services}

Table 2 shows the patterns of utilisation of better technical quality ANC services, and delivery and PNC services. Publicly managed HFs (53\%), ANC services provided by nursing staff (55\%), and those HFs from province seven (72\%) were found to have high proportion of utilisation of better technical quality ANC services compared to their reference groups. Women who attended at HFs with better capacity (60\%), who belonged to Brahmin/Chhetri ethnic groups (64\%) or who had attained 10th grade of education (62\%) utilised better quality ANC services. Conversely, women utilised better quality delivery and PNC services in private HFs (75\%), Janajati women (59\%), women aged 30 years or above (68\%), if doctors provided $\mathrm{MNH}$ services (60\%). However, only $11 \%$ of women from province two received better quality delivery and PNC services. Among seven provinces in Nepal, province two is located in the Southern part of the country and has a low literacy rate and densely populated [63], while province six has the lowest status of socioeconomic indicators and the remotest province [64].

\section{Determinants of utilisation of better technical quality MNH services}

Table 3 shows the logistic regression analysis of the utilisation of better quality $\mathrm{MNH}$ services. Out of the 18 independent variables examined for the utilisation of quality ANC services in bivariable regression analysis, seven variables including structural (women's ethnicity and education, management authority), intermediary (province, region), health system (HF capacity, types of health workers) were significantly positively associated with better quality ANC services. Out of 17 variables examined in the bivariable regression analysis, nine variables, which included structural (ethnicity, types of management), intermediary (province), health system (external supervision, feedback collection, types of providers, providers of PNC-mother, types of providers of PNC-newborn, mode delivery) were significantly associated with utilisation of better quality of delivery and PNC services.

In the multivariable logistic regression analyses, four variables (HF capacity, province, types of health providers, and staff's supervision) were significantly positively associated with utilising better-quality ANC services. Compared to women from province one, women living in province four (adjusted odds ratio $(\mathrm{aOR})=4.03 ; 95 \% \mathrm{CI}: 1.56,10.40)$ received better quality ANC services. Province four has a comparatively high number of HFs and a better road network to reach HFs [64], and it is a developed province with a higher human development index compared to other provinces. Women utilised better quality $(\mathrm{aOR}=2.89 ; 95 \% \mathrm{CI}: 1.33$, 6.29) ANC services if they received services from the nursing staff compared to physicians. If pregnant women 
Table 2 Utilisation of better technical quality of routine MNH services stratified by independent variables in Nepal, 2015

\begin{tabular}{|c|c|c|c|c|c|c|c|c|c|}
\hline \multicolumn{5}{|c|}{$\begin{array}{l}\text { Pregnant women attended HFs for their first ANC visit }(N=523) \text { who } \\
\text { received better quality ANC services }(\%)\end{array}$} & \multicolumn{5}{|c|}{$\begin{array}{l}\text { Postpartum women discharged from HFs }(N=309) \text { who received } \\
\text { better quality delivery and PNC services }(\%)\end{array}$} \\
\hline Determinants & Categories & $\begin{array}{l}\text { Total } \\
\text { frequency }\end{array}$ & $\begin{array}{l}\% \text { of better } \\
\text { quality }\end{array}$ & $p$ & Determinants & Categories & $\begin{array}{l}\text { Total } \\
\text { frequency }\end{array}$ & $\begin{array}{l}\% \text { of better } \\
\text { quality }\end{array}$ & $p$ \\
\hline Structural & & & & & Structural & & & & \\
\hline \multirow[t]{5}{*}{ Ethnicity } & $\begin{array}{l}\text { Brahmin/ } \\
\text { Chhetri }\end{array}$ & 103 & 63.8 & 0.022 & Ethnicity & $\begin{array}{l}\text { Brahmin/ } \\
\text { Chhetri }\end{array}$ & 155 & 57.1 & $<.<001$ \\
\hline & Janajatis & 155 & 51.9 & & & Janajatis & 66 & 58.9 & \\
\hline & Madhesi & 157 & 45.8 & & & Madhesi & 51 & 23.6 & \\
\hline & Dalit & 66 & 47.9 & & & Dalit & 37 & 40.4 & \\
\hline & Muslims & 43 & 27.1 & & Managed by & Private & 97 & 74.6 & \\
\hline \multirow[t]{3}{*}{ Education } & No schooling & 155 & 36.4 & 0.001 & & Public & 212 & 38.7 & $\begin{array}{l}< \\
0.001\end{array}$ \\
\hline & $\begin{array}{l}\text { Up to } 10 \\
\text { grades }\end{array}$ & 216 & 61.7 & & Intermediary & & & & \\
\hline & $\geq S L C$ & 152 & 46.5 & & Province & 1 & 24 & 42.3 & $\begin{array}{l}< \\
0.001\end{array}$ \\
\hline \multirow[t]{2}{*}{ Managed by } & Private & 73 & 30.7 & $\begin{array}{l}< \\
0.001\end{array}$ & & 2 & 46 & 11.2 & \\
\hline & Public & 450 & 52.9 & & & 3 & 110 & 69.0 & \\
\hline Intermediary & & & & & & 4 & 38 & 46.7 & \\
\hline \multirow[t]{7}{*}{ Province } & One & 89 & 43.4 & $\begin{array}{l}< \\
0.001\end{array}$ & & 5 & 48 & 58.1 & \\
\hline & Two & 154 & 32.9 & & & 6 & 19 & 55.6 & \\
\hline & Three & 116 & 51.5 & & & 7 & 23 & 26.6 & \\
\hline & Four & 25 & 69.8 & & $\begin{array}{l}\text { Women's age } \\
\text { (years) }\end{array}$ & $15-19$ & 36 & 44.5 & 0.013 \\
\hline & Five & 84 & 66.3 & & & $20-24$ & 130 & 38.9 & \\
\hline & Six & 20 & 65.5 & & & $25-29$ & 96 & 58.1 & \\
\hline & Seven & 35 & 72.1 & & & $\geq 30$ & 47 & 68.1 & \\
\hline \multirow[t]{3}{*}{ Waiting time } & Immediately & 149 & 47.2 & & $\begin{array}{l}\text { Companion in } \\
\text { delivery }\end{array}$ & No & 93 & 55.5 & 0.32 \\
\hline & Up to $30 \mathrm{~min}$ & 251 & 52.2 & 0.427 & & Yes & 216 & 47.6 & \\
\hline & $>30 \mathrm{~min}$ & 123 & 46.7 & & Health system & & & & \\
\hline \multirow[t]{3}{*}{ Region } & Mountain & 16 & 53.9 & 0.117 & HF capacity & Low & 123 & 59.9 & 0.160 \\
\hline & Hill & 172 & 57.9 & & & Medium & 105 & 45.4 & \\
\hline & Terai & 335 & 45.5 & & & High & 81 & 40.6 & \\
\hline \multirow[t]{4}{*}{$\begin{array}{l}\text { Women's age } \\
\text { (years) }\end{array}$} & $15-19$ & 120 & 53.8 & 0.782 & $\begin{array}{l}\text { Supervision of } \\
\text { staff }\end{array}$ & No & 119 & 66.3 & 0.010 \\
\hline & $20-24$ & 230 & 49.7 & & & Yes & 190 & 39.7 & \\
\hline & $25-29$ & 118 & 44.7 & & HF meeting & Never & 47 & 53.5 & 0.812 \\
\hline & $\geq 30$ & 55 & 52.8 & & & Sometimes & 50 & 55.0 & \\
\hline Health system & & & & & & Monthly & 211 & 48.0 & \\
\hline \multirow[t]{3}{*}{ HF capacity } & Low & 175 & 40.2 & 0.036 & Feedback & Yes & 249 & 55.2 & \\
\hline & Medium & 174 & 59.7 & & & No & 60 & 28.2 & \\
\hline & High & 174 & 48.6 & & QA activities & No & 214 & 45.3 & 0.120 \\
\hline \multirow[t]{2}{*}{ Facility types } & $\begin{array}{l}\text { PHCCs and } \\
\text { hospitals }\end{array}$ & 303 & 49.1 & 0.782 & & Yes & 95 & 60.5 & \\
\hline & HPs and clinics & 220 & 50.8 & & Aama program & No & 78 & 67.7 & 0.051 \\
\hline
\end{tabular}


Table 2 Utilisation of better technical quality of routine MNH services stratified by independent variables in Nepal, 2015 (Continued)

\begin{tabular}{|c|c|c|c|c|c|c|c|c|c|}
\hline \multicolumn{5}{|c|}{$\begin{array}{l}\text { Pregnant women attended HFs for their first ANC visit }(N=523) \text { who } \\
\text { received better quality ANC services }(\%)\end{array}$} & \multicolumn{5}{|c|}{$\begin{array}{l}\text { Postpartum women discharged from HFs }(N=309) \text { who received } \\
\text { better quality delivery and PNC services }(\%)\end{array}$} \\
\hline Determinants & Categories & $\begin{array}{l}\text { Total } \\
\text { frequency }\end{array}$ & $\begin{array}{l}\% \text { of better } \\
\text { quality }\end{array}$ & $p$ & Determinants & Categories & $\begin{array}{l}\text { Total } \\
\text { frequency }\end{array}$ & $\begin{array}{l}\% \text { of better } \\
\text { quality }\end{array}$ & $p$ \\
\hline \multirow{2}{*}{$\begin{array}{l}\text { Supervision of } \\
\text { staff }\end{array}$} & No & 172 & 41.4 & 0.087 & & Yes & 231 & 44.0 & \\
\hline & Yes & 351 & 54.0 & & $\begin{array}{l}\text { Decision to seek } \\
\text { care }\end{array}$ & Late & 25 & 60.3 & 0.403 \\
\hline \multirow[t]{3}{*}{ HF meeting } & Never & 64 & 50.9 & 0.961 & & Timely & 284 & 49.0 & \\
\hline & Sometimes & 81 & 47.8 & & Providers & Nurse & 203 & 43.1 & 0.006 \\
\hline & Monthly & 378 & 50.1 & & & Doctors & 106 & 63.1 & \\
\hline \multirow[t]{2}{*}{ Feedback } & Yes & 326 & 52.2 & 0.320 & & & & & \\
\hline & No & 197 & 45.9 & & & & & & \\
\hline \multirow[t]{2}{*}{ QA activities } & No & 392 & 50.0 & 0.921 & PNC mothers & Nurses & 137 & 37.8 & 0.006 \\
\hline & Yes & 131 & 49.3 & & & Doctor & 172 & 59.7 & \\
\hline \multirow[t]{2}{*}{ Waiting area } & No & 39 & 38.2 & 0.309 & PNC-Newborn & Nurses & 134 & 35.7 & 0.003 \\
\hline & Yes & 484 & 50.7 & & & Doctor & 175 & 60.8 & \\
\hline \multirow[t]{4}{*}{ HW category } & GP/Specialists & 77 & 29.5 & 0.004 & First baby & No & 136 & 51.8 & 0.576 \\
\hline & MBBS & 23 & 26.3 & & & Yes & 173 & 48.5 & \\
\hline & Nursing & 392 & 55.0 & & Delivery & Normal & 239 & 46.4 & 0.047 \\
\hline & Paramedics & 14 & 31.5 & & & Assisted & 70 & 62.0 & \\
\hline \multirow{2}{*}{$\begin{array}{l}\text { Supervision of } \\
\text { staff }\end{array}$} & No & 265 & 45.8 & 0.209 & & & & & \\
\hline & Yes & 258 & 54.0 & & & & & & \\
\hline \multirow[t]{2}{*}{ Problem felt } & No & 224 & 56.1 & 0.067 & & & & & \\
\hline & Yes & 299 & 45.1 & & & & & & \\
\hline \multirow[t]{2}{*}{ Need to pay } & Yes & 168 & 43.7 & 0.135 & & & & & \\
\hline & No & 355 & 52.7 & & & & & & \\
\hline
\end{tabular}

Note: $p$-values based on Fisher exact test

received ANC services from health providers who received specific supervision in the past 4 months, the odds were higher $(\mathrm{aOR}=1.71 ; 95 \% \mathrm{CI}: 1.01,2.92)$ for better quality ANC services compared to their reference category. Three variables (management authority, province, providers of PNC-newborn) were significantly associated with utilisation of better quality of delivery and PNC services after adjusting all covariates at $p<0.05$. The odds were more than two times higher for the utilisation of better technical quality delivery and PNC services $(\mathrm{aOR}=2.63 ; 95 \% \mathrm{CI}: 1.14,6.08)$ if women received services at private HFs. Women from province two had $85 \%$ lower odds of the utilisation of better technical quality delivery and PNC services $(\mathrm{aOR}=0.15 ; 95 \% \mathrm{CI}$ : 0.03, 0.63) (Table 3).

\section{Discussion}

This study demonstrated that women utilised better quality care from private than public HFs. In Nepal, the number of private HFs has increased since 1995, but basic health services, including $\mathrm{MNH}$ services, are not freely available in private HFs. However, women utilised poor quality delivery and PNC services in HFs of province two. Compared to other provinces, province two lies in the Southern part of the country, bordered with north India, has better access and transportation systems. In addition, women in this province generally have low literacy and awareness of health information on their health needs, and availability of health services in HFs [63]. Health staff supervised by a higher authority provided better quality MNH services. Supervision and monitoring of HFs and staff at a lower level can improve the management and capacity for better quality services delivery [65]. Further, women utilised better technical quality of $\mathrm{MNH}$ services from the nursing staff than physicians' services. In Nepal, trained SBAs, usually auxiliary nurse midwives (all are females) provide routine $\mathrm{MNH}$ services, thus, $\mathrm{MNH}$ services provided by nursing cadre can be argued as of better technical quality.

Women utilised better technical quality of quality ANC and institutional delivery in private HFs. In Nepal, while the share of private HFs in urban areas is 
Table 3 Binomial logistic regression for the determinants of utilisation of better technical quality of routine MNH services in Nepal, 2015

\begin{tabular}{|c|c|c|c|c|c|c|c|}
\hline \multicolumn{4}{|c|}{ Pregnant women attended HFs for their first ANC visit $(\mathrm{N}=523)$} & \multicolumn{4}{|c|}{ Postpartum women discharged from HFs $(\mathrm{N}=309)$} \\
\hline Determinants & Categories & cOR $(95 \% \mathrm{Cl})$ & aOR $(95 \% \mathrm{Cl})$ & Determinants & Categories & COR $(95 \% \mathrm{Cl})$ & aOR $(95 \% \mathrm{Cl})$ \\
\hline Structural & & & & Structural & & & \\
\hline \multirow[t]{5}{*}{ Ethnicity (women) } & Brahmin/Chhetri & 1.00 & & Ethnicity (women) & $\begin{array}{l}\text { Brahmin/ } \\
\text { Chhetri }\end{array}$ & 1.00 & \\
\hline & Janajatis & $0.46(0.22,0.94) *$ & & & Janajatis & $1.07(0.57,2.03)$ & \\
\hline & Madhesi & $\begin{array}{l}0.33(0.16,0.69) \\
* *\end{array}$ & & & Madhesi & $\begin{array}{l}0.23(0.10,0.51) \\
* * *\end{array}$ & \\
\hline & Dalit & $0.43(0.20,0.94) *$ & & & Dalit & $0.51(0.21,1.26)$ & \\
\hline & Muslims & $\underset{* *}{0.20}(0.08,0.53)$ & & Managed by & Public & 1.00 & 1.00 \\
\hline \multirow[t]{3}{*}{ Education } & No schooling & 1.00 & & & Private & $\begin{array}{l}4.64(2.05,10.48) \\
* * *\end{array}$ & $\begin{array}{l}2.63(1.14,6.08) \\
*\end{array}$ \\
\hline & Up to 10 grades & $2.21(1.20,4.08) *$ & & Intermediary & & & \\
\hline & SLC and above & $1.86(0.99,3.50)$ & & Province & One & 1.00 & 1.00 \\
\hline \multirow[t]{2}{*}{ Managed by } & Public & 1.00 & & & Two & $0.17(0.04,0.67) *$ & $\begin{array}{l}0.15(0.03,0.63) \\
*\end{array}$ \\
\hline & Private & $0.50(0.28,0.87) *$ & & & Three & $3.03(0.83,11.08)$ & $2.04(0.57,7.31)$ \\
\hline Intermediary & & & & & Four & $1.19(0.29,4.85)$ & $0.94(0.21,4.21)$ \\
\hline \multirow[t]{7}{*}{ Province } & One & 1.00 & 1.00 & & Five & $1.89(0.46,7.70)$ & $1.58(0.36,7.00)$ \\
\hline & Two & $0.72(0.26,1.94)$ & $0.52(0.19,1.38)$ & & Six & $1.71(0.47,6.20)$ & $\begin{array}{l}2.94(0.68 \\
12.69)\end{array}$ \\
\hline & Three & $1.82(0.72,4.60)$ & $2.11(0.84,5.32)$ & & Seven & $0.49(0.13,1.91)$ & $0.59(0.15,2.33)$ \\
\hline & Four & $\begin{array}{l}4.55(1.58,13.08) \\
* *\end{array}$ & $\begin{array}{l}4.03(1.56,10.40) \\
* *\end{array}$ & $\begin{array}{l}\text { Women's age } \\
\text { (years) }\end{array}$ & $15-19$ & 1.00 & \\
\hline & Five & $2.32(0.88,6.08)$ & $1.60(0.63,4.04)$ & & $20-24$ & $0.80(0.39,1.61)$ & \\
\hline & Six & $\begin{array}{l}4.01(1.14,14.11) \\
*\end{array}$ & $3.28(0.90,12.01)$ & & $25-29$ & $1.73(0.78,3.86)$ & \\
\hline & Seven & $\begin{array}{l}3.88(1.43,10.49) \\
* *\end{array}$ & $2.77(0.94,8.16)$ & & $\geq 30$ & $2.67(0.96,7.38)$ & \\
\hline \multirow[t]{3}{*}{ Waiting time } & Immediately & 1.00 & & $\begin{array}{l}\text { Delivery } \\
\text { Companion }\end{array}$ & No & 1.00 & \\
\hline & Up to $30 \mathrm{~min}$ & $1.22(0.70,2.10)$ & & & Yes & $0.73(0.39,1.37)$ & \\
\hline & $>30 \mathrm{~min}$ & $0.98(0.50,1.92)$ & & & & & \\
\hline \multirow[t]{3}{*}{ Region } & Terai & 1.00 & & Health system & & & \\
\hline & Mountain & $1.95(0.48,7.89)$ & & HF capacity & Low & 1.00 & \\
\hline & Hill & $\begin{array}{l}1.84(1.08,3.15) \\
*\end{array}$ & & & Medium & $0.56(0.23,1.32)$ & \\
\hline \multirow{4}{*}{$\begin{array}{l}\text { Women's age } \\
\text { (years) }\end{array}$} & $15-19$ & 1.00 & & & High & $0.46(0.20,1.05)$ & \\
\hline & $20-24$ & $1.42(0.69,2.90)$ & & $\begin{array}{l}\text { Supervision of } \\
\text { staff }\end{array}$ & No & 1.00 & \\
\hline & $25-29$ & $1.13(0.58,2.21)$ & & & Yes & $0.33(0.14,0.78) *$ & \\
\hline & $\geq 30$ & $1.14(0.44,2.99)$ & & HF Meeting & Never & 1.00 & \\
\hline \multirow[t]{2}{*}{ Facility types } & $\begin{array}{l}\text { PHCCs and } \\
\text { hospitals }\end{array}$ & 1.00 & & & Sometimes & $1.06(0.20,5.72)$ & \\
\hline & HPs and clinics & $0.78(0.43,1.39)$ & & & Monthly & $0.80(0.35,1.85)$ & \\
\hline Health system & & & & $\begin{array}{l}\text { Feedback } \\
\text { collection }\end{array}$ & Yes & 1.00 & \\
\hline HF capacity & Low & 1.00 & 1.00 & & No & $0.32(0.16,0.64) * *$ & \\
\hline
\end{tabular}


Table 3 Binomial logistic regression for the determinants of utilisation of better technical quality of routine MNH services in Nepal, 2015 (Continued)

\begin{tabular}{|c|c|c|c|c|c|c|c|}
\hline \multicolumn{4}{|c|}{ Pregnant women attended HFs for their first ANC visit $(N=523)$} & \multicolumn{4}{|c|}{ Postpartum women discharged from HFs $(\mathrm{N}=309)$} \\
\hline Determinants & Categories & cOR $(95 \% \mathrm{Cl})$ & aOR $(95 \% \mathrm{Cl})$ & Determinants & Categories & COR $(95 \% \mathrm{Cl})$ & aOR $(95 \% \mathrm{Cl})$ \\
\hline & Medium & $\begin{array}{l}2.21(1.07,4.56) \\
*\end{array}$ & $2.12(1.03,4.35) *$ & QA activities & No & 1.00 & \\
\hline & High & $1.41(0.67,2.97)$ & $1.27(0.55,2.94)$ & & Yes & $1.85(0.85,4.02)$ & \\
\hline \multirow{2}{*}{$\begin{array}{l}\text { Supervision of } \\
\text { staff }\end{array}$} & No & 1.00 & & Aama program & No & 1.00 & \\
\hline & Yes & $1.79(0.91,3.52)$ & & & Yes & $0.37(0.14,1.02)$ & \\
\hline \multirow[t]{3}{*}{ HF meeting } & Never & 1.00 & & Decision & No & 1.00 & \\
\hline & Sometimes & $0.74(0.22,2.47)$ & & & Timely & $0.63(0.21,1.89)$ & \\
\hline & Monthly & $1.04(0.43,2.53)$ & & Providers & Nurse & 1.00 & \\
\hline \multirow{2}{*}{$\begin{array}{l}\text { Feedback } \\
\text { collection }\end{array}$} & Yes & 1.00 & & & Doctors & $2.26(1.27,4.04) * *$ & \\
\hline & No & $0.75(0.41,1.37)$ & & & & & \\
\hline \multirow[t]{2}{*}{ Quality assurance } & No & 1.00 & & & & & \\
\hline & Yes & $1.04(0.55,1.97)$ & & PNC Mothers & Nurses & 1.00 & \\
\hline \multirow[t]{2}{*}{ Waiting area } & No & 1.00 & & & Doctor & $2.44(1.29,4.62) * *$ & \\
\hline & Yes & $1.39(0.53,3.66)$ & & PNC Newborn & Nurses & 1.00 & 1.00 \\
\hline \multirow[t]{4}{*}{ HWs category } & GP/Specialists & 1.00 & 1.00 & & Doctor & $2.79(1.44,5.42) * *$ & $\begin{array}{l}2.14(1.13,4.04) \\
*\end{array}$ \\
\hline & MBBS & $0.85(0.18,4.07)$ & $1.00(0.23,4.35)$ & First baby & No & 1.00 & \\
\hline & Nursing & $2.06(1.07,3.94) *$ & $\underset{* *}{2.89(1.33,6.29)}$ & & Yes & $0.88(0.55,1.40)$ & \\
\hline & Paramedics & $0.91(0.21,3.96)$ & $0.89(0.21,3.74)$ & Delivery & Normal & 1.00 & \\
\hline \multirow[t]{2}{*}{ Staff supervision } & No & 1.00 & 1.00 & & Assisted & $1.88(1.00,3.52) *$ & \\
\hline & Yes & $1.71(0.96,3.03)$ & $1.71(1.01,2.92) *$ & & & & \\
\hline \multirow{2}{*}{$\begin{array}{l}\text { Problem felt } \\
\text { (clients) }\end{array}$} & No & 1.00 & & & & & \\
\hline & Yes & $0.70(0.42,1.14)$ & & & & & \\
\hline \multirow[t]{2}{*}{ Need to pay } & Yes & 1.00 & & & & & \\
\hline & No & $1.19(0.71,1.99)$ & & & & & \\
\hline
\end{tabular}

Significance at ${ }^{*} p<0.01, * p<0.05$. Variables which had $p<0.2$ included in the final model for each outcome variable. For each outcome variable, independent binomial logistic regression analysis was consudcted adjusting for covariates listed in the respective column. Goodness of fit test (Hosmer Lemeshow test) for utilisation of technical quality for ANC services ( $p=0.896)$. Goodness of fit test (Hosmer Lemeshow test) for utilisation of technical quality of delivery and PNC services ( $p=0.793$ ).

These figures show that our models are the best fit.

increasing, private health services, including routine $\mathrm{MNH}$ services, are expensive due to high OOP expenditure and lack of financial risk protection in health care $[34,66]$, may charge up to 15 USD per consultation [67]. Such a high cost of care could limit access to quality health services, especially for disadvantaged women and exacerbate health inequities. Women's access to $\mathrm{MNH}$ services in private HFs can be improved through the scaling up of the Safe Delivery Incentive Program (SDIP) in additional private HFs. In addition, the NHIP can be linked with routine private $\mathrm{MNH}$ services through which OOP expenses can be reimbursed [36]. Furthermore, women should receive quality health services irrespective of the types of HFs management (private or public). Adopting a public-private partnership (PPP) model could increase disadvantaged population's use of quality
MNH services in private sector HFs. Concurrently, the quality of care in public sector HFs needs to be improved as well for better delivering quality care for $\mathrm{MNH}$ outcomes. Improving the quality of care in public HFs is particularly important in Nepal as peripheral and public HFs provide more than $80 \%$ of maternity services [32].

In this study, level of education and ethnicity were not associated with utilisation of quality $\mathrm{MNH}$ services in the final regression model despite being significantly associated in bivariable analysis. Further analysis of household survey data suggests that women of disadvantaged ethnicity or low level of education have poor access to quality ANC services in Nepal [15], and low effective coverage of $\mathrm{MNH}$ services [17]. Usually, in Nepal, women of privileged groups prefer to receive $\mathrm{MNH}$ 
services at private HFs [66]. Further studies could confirm the level of quality of care utilised by women with educational and ethnic disadvantages in Nepal.

This study showed women utilised better quality ANC services if they attended HFs with better health system inputs (structural quality). This underscores the need for building HF capacity through system inputs, including trained health workers, equipment, medicine, supplies and protocols/guideline, infrastructure. Health system readiness/inputs are hindered by several supply-side barriers, including poor health system readiness and system governance, lack of health workforce accountability [68, 69], including lack of adequate trained staff [70]. Therefore, program and policy efforts should focus on improved management and health governance systems for better HF capacity for quality MNH services.

Women received poor quality MNH services in HFs of province two, where the highest number of childbirths occur annually [32]. Therefore, improving the quality of HFs in province two should be a priority in addressing inequities in access to quality care and health outcomes. A previous study of care for NCDs also found HFs of province two had poor health system readiness [25]. In addition, studies also suggest women's access to reproductive, maternal and child health issues need to be improved [32, 63]. Women in the province two [37], especially those who are more disadvantaged, also experience some demand and supply-side barriers in accessing quality MNH services [32, 63], including lack of trained SBAs in HFs, inadequate supply of medicine, equipment and lack of necessary infrastructure for better HF capacity [26]. Demand-side barriers include poor access to information and awareness, language barriers, ethnic disadvantage, and sociocultural barriers such as shyness, especially with male health care providers [68, 71]. Thus, the provincial and local governments of this province could recruit trained staff from the local municipalities who can understand local context, languages, culture, and address context-specific issues.

The current study identified if staff were supervised by a higher authority in the last 4 months, women utilised better technical quality MNH services in HFs. Studies suggest staff supervision can improve quality $\mathrm{MNH}$ services: by improving management functions and improving technical capacity for the delivery of clinical services $[72,73]$. Supervision and monitoring of HFs and HWs at the peripheral HFs could improve the quality of health services in Nepal [65]. In Tanzania, a study reported that supervision visits improved health management functions in peripheral HFs and delivered better quality primary health care (PHC) services [74]. Therefore, regular supervision and monitoring, onsite coaching of health workers at lower-level HFs are vital to improving the utilisation of better quality MNH services in Nepal.
Finally, while in Nepal, trained nurse-midwives provide much of the routine MNH services, especially normal deliveries and immediate newborn care services for normal neonates. The current study identified that women who received care from nursing staff also received better quality services. In Nepal, nursing staff are females only (since 2020, males are also allowed to study nursing program). Culturally, Nepali women feel more comfortable sharing reproductive health needs with the nursing cadre, especially reproductive and maternal newborn and child health services [75]. Evidence suggests women across South Asia prefer nursing staff and female physicians compared to male health providers $[72,76]$. In the context of the federal health system governance of Nepal, local governments have the funds and authority for design and implementation of context-specific health programs [30], the local recruitment of nurse-midwives could be possible in the peripheral HFs. Though current study identified that nurse-midwives provided better routine $\mathrm{MNH}$ services for normal deliveries and routine newborn care, but are often poorly skilled in handling vulnerable newborns (e.g., sick newborns, premature babies) [77]. Therefore, nursing staffs need further training and support, especially with newborns requiring higher levels of care, such as low birth weight babies, preterm, or babies with a breathing problem. As doctors are usually not available at the lower level of HFs, transferring skills to nurse-midwives who work at the lower level is critical.

\section{Implications for policy and programs}

This study has some policy and programmatic implications. Firstly, this study suggests improving the quality of care in public facilities. Secondly, context-specific interventions need to implement at peripheral HFs; provision of local health staff, including nurse-midwives, could improve the delivery and utilisation of quality $\mathrm{MNH}$ services. Importantly, provincial and local governments should focus on the strengthening health system for better health service readiness, delivery and utilisation of quality MNH services. Thirdly, peripheral HFs and health workers should receive monitoring and onsite coaching for improved quality of care for women/newborns with disadvantaged groups.

\section{Strengths and limitations of the study}

This study has some strengths and limitations. First, this study has analysed data from nationally representative health facility survey with multiple data sources. Secondly, this study created the composite measure of quality assessment and determinants of its utilisation. This study has some limitations, firstly, findings of this study do not predict the causality rather shows the correlation. Secondly, some of the categories of the independent 
variable (e.g., province) have a small sample size (e.g., province six, 19 postpartum women), there is likely to be a large degree of random error. Categories with small sample sizes should be interpreted with caution due to the inadequate precision, and the magnitude of these effect estimates need to be confirmed in future studies with larger sample sizes. Thirdly, this study represents the status of quality of care at the time of data collection in 2015 [29] as there has not been a recent nationwide survey and available data to assess the utilisation of quality MNH services. Finally, this study represents the quality of health care utilisation 5 years ago; as the country has changed from its unitary governance to federal governance, the situation may have changed after the implementation of the federal health system.

\section{Conclusions}

Women utilised better quality $\mathrm{MNH}$ services in private HFs; nursing staff provided better quality MNH services. Several approaches can be implemented to improve the utilisation of better technical quality of $\mathrm{MNH}$ services. Access to ANC services in privately managed HFs could be improved through the implementation of the publicprivate-partnership (PPP) strategy such as the demandside financial program (e.g., SDIP). Routine MNH services can be made available free of cost at private sector HFs if the National Safe Motherhood Program is linked with the NHIP. Provincial and local governments require to strengthen the local/municipal health systems to designand implement context-specific interventions such as trained local SBAs, onsite coaching of health staff, supervision, and monitoring of HFs, especially usually visit peripheral HFs.

\section{Abbreviations}

ANC: Antenatal Care; LMICs: Low and lower-middle-income countries: MNH: Maternal and newborn health; PNC: Postnatal Care; SDIP: Safe Delivery Incentive Program; SPA: Service Provision Assessment; HF: Health Facility; SARA: Service Availability and Readiness Assessment; SDGs: Sustainable Development Goals; HFs: Health facilities; QA: Quality assurance; PHCC: Primary health care centres; HP: Health post; PPP: Public-privatepartnership; UHC: Univesal Health Coverage

\section{Supplementary Information}

The online version contains supplementary material available at https://doi. org/10.1186/s12992-021-00752-x.

Additional file 1 : Table S1. Description of independent variables included in the utilisation of better quality MNH services in Nepal. Table S2. Items included in the HF capacity assessment for antenatal care services. Table S3. Items included in the HF capacity assessment for delivery and postnatal services. Table S4. Observations and uptake of ANC interventions for the measurement of the technical quality of ANC services. Table S5. Observations and uptake of delivery and PNC interventions for the measurement of the technical quality of delivery and PNC services.

\section{Acknowledgements}

This manuscript is a part of the first author's (RBK) doctoral thesis at the School of Public Health, the University of Queensland. To undertake the PhD degree, RBK was supported by the Research Training Program, UQ International, and Career Development Extension Scholarships by the University of Queensland, Brisbane, QLD, Australia. We thank the Demographic and Health Survey program for providing access to the data sets. The first author (RBK) would like to thank Dr. Melinda Protani, and Dr. Rajendra Karkee for their guidance in his doctoral candidature.

\section{Authors' contributions}

RBK conceived of the study, performed the statistical analysis, and prepared a first draft of the manuscript. YA, and JD supervised the study and provided critical comments on the draft manuscript. All authors read and agreed on the final version of the manuscript.

\section{Funding}

No funding received for the development of this manuscript.

\section{Availability of data and materials}

Data used in this study are publicly available secondary data obtained from the DHS (https://dhsprogram.com/data/available-datasets.cfm) program.

\section{Declarations}

\section{Ethics approval and consent to participate}

We used secondary data from the Nepal SPA 2015. This survey was approved by an ethical review board of Nepal Health Research Council, Nepal, and ICF Marco International, Maryland, USA. The Ministry of Health and Population (MOHP) (Nepal) oversaw the overall research process of the SPA 2015. The Nepal SPA data are publicly available for further analysis, and data were deidentified of the research participants. This study did not require ethical approval from respective institutions. However, the first author took approval for the download and use of the dataset for this study. This study was a part of the first author's PhD thesis. His PhD proposal was approved by the University of Queensland and got ethical exemption (clearance number: 2017002080) for the use of secondary data for the PhD project.

\section{Consent for publication}

Not applicable.

\section{Competing interests}

The authors declared that they have no competing interests.

\section{Author details}

${ }^{1}$ School of Public Health, Faculty of Medicine, University of Queensland, Brisbane, Australia. ${ }^{2}$ Health Social Science and Development Research Institute, Kathmandu, Nepal. ${ }^{3}$ School of Public Health and Social Work, Queensland University of Technology, Brisbane, Australia.

Received: 3 June 2021 Accepted: 12 August 2021

Published online: 06 September 2021

\section{References}

1. Ministry of Health, New ERA, The DHS Program ICF (2017). Nepal Demographic and Health Survey. Kathmandu, Nepal: Ministry of Health, Nepal; 2016. Available from https://www.dhsprogram.com/pubs/pdf/FR336/ FR336.pdf. Accessed 12 Jul 2020.

2. Bhatt H, Tiwari S, Ensor T, Ghimire DR, Gavidia T. Contribution of Nepal's free delivery care policies in improving utilisation of maternal health services. Int J Health Policy Manag. 2018;7(7):645-55. https://doi.org/10.151 71/ijhpm.2018.01.

3. Ensor T, Bhatt H, Tiwari S. Incentivizing universal safe delivery in Nepal: 10 years of experience. Health Policy Plan. 2017;32(8):1185-92. https://doi.org/1 0.1093/heapol/czx070.

4. Randive B, San Sebastian M, De Costa A, Lindholm L. Inequalities in institutional delivery uptake and maternal mortality reduction in the context of cash incentive program, Janani Suraksha Yojana: Results from nine states in India. Soc Sci Med. 2014;123:1-6. https://doi.org/10.1016/j.socscimed.2 014.10.042. 
5. Donabedian A. The quality of care. How can it be assessed? JAMA. 1988; 260(12):1743-8. https://doi.org/10.1001/jama.1988.03410120089033.

6. Alhassan RK, Duku SO, Janssens W, Nketiah-Amponsah E, Spieker N, van Ostenberg P, et al. Comparison of Perceived and Technical Healthcare Quality in Primary Health Facilities: Implications for a Sustainable National Health Insurance Scheme in Ghana. PLoS One. 2015;10(10):e0140109. https://doi.org/10.1371/journal.pone.0140109.

7. Kruk ME, Gage AD, Arsenault C, Jordan K, Leslie HH, Roder-DeWan S, et al. High-quality health systems in the Sustainable Development Goals era: time for a revolution. Lancet Glob Health. 2018;6(11):e1196-252. https://doi.org/1 0.1016/S2214-109X(18)30386-3.

8. WHO: Delivering quality health services: a global imperative for universal health coverage. 2018

9. Nove A, Friberg IK, de Bernis L, McConville F, Moran AC, Najjemba M, et al. Potential impact of midwives in preventing and reducing maternal and neonatal mortality and stillbirths: a Lives Saved Tool modelling study. Lancet Glob Health. 2021;9(1):e24-32. https://doi.org/10.1016/S2214-109X(2 0)30397-1

10. Tuncalp W, WM MLC, Oladapo OT, Gulmezoglu AM, Bahl R, Daelmans B, et al. Quality of care for pregnant women and newborns-the WHO vision. BJOG. 2015;122(8):1045-9. https://doi.org/10.1111/1471-0528.13451.

11. Shengelia B, Tandon A, Adams OB, Murray CJL. Access, utilization, quality, and effective coverage: An integrated conceptual framework and measurement strategy. Soc Sci Med. 2005;61(1):97-109. https://doi.org/10.1 016/j.socscimed.2004.11.055.

12. Chou VB, Walker N, Kanyangarara M. Estimating the global impact of poor quality of care on maternal and neonatal outcomes in 81 low- and middleincome countries: A modeling study. PLoS Med. 2019;16(12):e1002990. https://doi.org/10.1371/journal.pmed.1002990.

13. Mehata S, Paudel YR, Dariang M, Aryal KK, Paudel S, Mehta R, et al. Factors determining satisfaction among facility-based maternity clients in Nepal. BMC Pregnancy Childbirth. 2017;17(1):319. https://doi.org/10.1186/s12884-01 7-1532-0.

14. Mooney AC, Campbell CK, Ratlhagana M-J, Grignon JS, Mazibuko S, Agnew E, et al. Beyond Social Desirability Bias: Investigating Inconsistencies in SelfReported HIV Testing and Treatment Behaviors Among HIV-Positive Adults in North West Province, South Africa. AIDS Behav. 2018;22(7):2368-79. https://doi.org/10.1007/s10461-018-2155-9.

15. Joshi C, Torvaldsen S, Hodgson R, Hayen A. Factors associated with the use and quality of antenatal care in Nepal: a population-based study using the demographic and health survey data. BMC Pregnancy Childbirth. 2014;14(1): 94. https://doi.org/10.1186/1471-2393-14-94.

16. Adhikari M, Chalise B, Bista B, Pandey AR, Upadhyaya DP. Sociodemographic correlates of antenatal care visits in Nepal: results from Nepal Demographic and Health Survey 2016. BMC Pregnancy Childbirth. 2020;20(1):513. https:// doi.org/10.1186/s12884-020-03218-X.

17. Khatri R, Durham J, Karkee R, Assefa Y. Patterns and determinants of effective coverage of routine maternal and newborn health visits in Nepal: Analysis of the 2016 Demographic and Health Survey (2021) [Preprint]. Avaiable from: https://doi.org/10.21203/rs.3.rs-347305/v1.

18. Wang W, Mallick L, Allen C, Pullum T. Effective coverage of facility delivery in Bangladesh, Haiti, Malawi, Nepal, Senegal, and Tanzania. PLoS One. 2019; 14(6):e0217853. https://doi.org/10.1371/journal.pone.0217853.

19. KC A, Singh DR, Upadhyaya MK, Budhathoki SS, Gurung A, Malqvist M. Quality of Care for Maternal and Newborn Health in Health Facilities in Nepal. Matern Child Health J. 2020;24(Suppl 1):31-8. https://doi.org/10.1007/ s10995-019-02846-w.

20. Leslie HH, Spiegelman D, Zhou X, Kruk ME. Service readiness of health facilities in Bangladesh, Haiti, Kenya, Malawi, Namibia, Nepal, Rwanda, Senegal, Uganda and the United Republic of Tanzania. Bull World Health Organ. 2017;95(11):738-48. https://doi.org/10.2471/BLT.17.191916.

21. Paudel YR, Mehata S, Paudel D, Dariang M, Aryal KK, Poudel P, et al. Women's Satisfaction of Maternity Care in Nepal and Its Correlation with Intended Future Utilization. Int J Reprod Med. 2015;2015:783050.

22. Karkee R, Lee AH, Pokharel PK. Womens' perception of quality of maternity services: a longitudinal survey in Nepal. BMC Pregnancy Childbirth. 2014; 14(1):45. https://doi.org/10.1186/1471-2393-14-45.

23. Karkee $\mathrm{R}$, Lee $\mathrm{AH}$, Binns $\mathrm{CW}$. Bypassing birth centres for childbirth: an analysis of data from a community-based prospective cohort study in Nepal. Health Policy Plan. 2015;30(1):1-7. https://doi.org/10.1093/heapol/ czt090.
24. Khatri RB, Dangi TP, Gautam R, Shrestha KN, Homer CSE. Barriers to utilization of childbirth services of a rural birthing center in Nepal: A qualitative study. PLoS One. 2017;12(5):e0177602. https://doi.org/10.1371/ journal.pone.0177602.

25. Ghimire U, Shrestha N, Adhikari B, Mehata S, Pokharel Y, Mishra SR. Health system's readiness to provide cardiovascular, diabetes and chronic respiratory disease related services in Nepal: analysis using 2015 health facility survey. BMC Public Health. 2020;20(1):1163. https://doi.org/10.1186/ s12889-020-09279-z.

26. Lama TP, Munos MK, Katz J, Khatry SK, LeClerg SC, Mullany LC. Assessment of facility and health worker readiness to provide quality antenatal, intrapartum and postpartum care in rural Southern Nepal. BMC Health Serv Res. 2020;20(1):16. https://doi.org/10.1186/s12913-019-4871-x.

27. MOHP [Nepal]: Annual health report. 2019.

28. Mishra SR, Lygidakis C, Neupane D, Gyawali B, Uwizihiwe JP, Virani SS, et al. Combating non-communicable diseases: potentials and challenges for community health workers in a digital age, a narrative review of the literature. Health Policy Plan. 2019;34(1):55-66. https://doi.org/10.1093/hea pol/czy099.

29. Ministry of Health/Nepal, New ERA/Nepal, Nepal Health Sector Support Program - NHSSP/Nepal, ICF. Nepal Health Facility Survey 2015. Kathmandu: Ministry of Health and ICF; 2017.

30. Thapa R, Bam K, Tiwari P, Sinha TK, Dahal S. Implementing federalism in the health system of Nepal: Opportunities and challenges. Int J Health Policy Manag. 2019;8(4):195-8. https://doi.org/10.15171/ijhpm.2018.121.

31. CA Secretariat [Nepal]: Constitution of Nepal 2015.Kathmandu: Constituent Assembly Secretariat. 2015

32. MOHP [Nepal]. Annual Report, Department of Health Services 2075/2076 (2018/2019). In: Ministry of Health and Population. Kathmandu: Ministry of Health and Population, Department of Health Services; 2020

33. Number of Health Facilities in Nepal. Available from https://heoc.mohp.gov. $\mathrm{np} /$ service/number-of-health-facilities-in-nepal/. Accessed 1 June 2021.

34. Sapkota T, Houkes I, Bosma H. Vicious cycle of chronic disease and poverty: a qualitative study in present day Nepal. International Health. 2020;13(1):3038. https://doi.org/10.1093/inthealth/ihaa016.

35. Ministry of Health and Population, Governmemt of Nepal. Nepal National Health Accounts 2012/13-2015/16. Ministry of Health and Population. Kathmahdu: 2018. Available from Nepal National Health Accounts 2012/13 to $2015 / 16$ (who.int)

36. Ranabhat $\mathrm{CL}$, Subedi R, Karn S. Status and determinants of enrollment and dropout of health insurance in Nepal: an explorative study. Cost Eff Resour Alloc. 2020;18(1):40. https://doi.org/10.1186/s12962-020-00227-7.

37. Khatri RB. Towards equity of maternal and newborn health services in Nepal. PhD Thesis. Australia: The University of Queensland; 2021.

38. Khanal GN. Conditional cash transfer policies in maternal health service utilization in Nepal: Analysis of safe delivery incentive program (Aama Surakshya Karyakram) using Kingdon's multiple streams framework. Int J Health Plann Manag. 2019;34(1):e131-41. https://doi.org/10.1002/hpm.2691.

39. MoHP [Nepal]. Nepal's Every Newborn Action Plan. In: Minitry of Health, Government of Nepal; 2016.

40. Ministry of Health and Population. National Health Policy 2014. Government of Nepal, Ministry of Health and Population; 2014.

41. MOHP [Nepal]. National health policy 2019. Ministry of Health and Population. Kathmandu: 2019. Available from National Health Policy - 2019 | Nepal (English Version) (publichealthupdate.com).

42. MOHP [Nepal]. Nepal health sector strategy 2015-2020. Kathmandu: Ministry of Health and Population; 2015.

43. SDG 3: Ensure healthy lives and promote wellbeing for all at all ages. [cited 03/05/2021]. Available from: https://www.who.int/sdg/targets/en/.

44. FWD: Nepal Safe Motherhood and Newborn Health Road Map 2030 Kathmandu: Family Welfare Division, Ministry of Health and Population; 2019.

45. National Planning Commission. Sustainable Development Goals, 2016-2030, National Report. Kathmandu: Government of Nepal, National Planning Commission; 2015

46. Nepal Demographics Profile. [cited 03/05/2021]. Available from https:// www.indexmundi.com/nepal/demographics_profile.html.

47. NPC [Nepal]. Nepal multidimensional poverty index analysis towards action. Kathmandu: National Planning Commission, Government of Nepal, Oxford Poverty and Human Development Initiative, University of Oxford; 2018.

48. Nepal: Economy. [cited 05/05/2021] Available from https://www.adb.org/ countries/nepal/economy. 
49. WHO. Service availability and readiness assessment (SARA): an annual monitoring system for service delivery: reference manual. Geneva: WHO; 2013. Available from SARA_Reference_Manual_Chapter1.pdf (who.int).

50. Conway K, Akseer N, Subedi RK, Brar S, Bhattarai B, Dhungana RR, et al. Drivers of stunting reduction in Nepal: a country case study. Am J Clin Nutr. 2020;112(Supplement_2):844S-59S. https://doi.org/10.1093/ajcn/nqaa218.

51. Mahato PK, Waithaka E, van Teijlingen E, Pant PR, Biswas A. Social autopsy: a potential health-promotion tool for preventing maternal mortality in lowincome countries. WHO South East Asia J Public Health. 2018;7(1):24-8. https://doi.org/10.4103/2224-3151.228424.

52. WHO. A conceptual framework for action on the social determinants of health. Geneva: World Health Organization; 2010.

53. Samuels F, Amaya AB, Balabanova D. Drivers of health system strengthening: learning from implementation of maternal and child health programmes in Mozambique, Nepal and Rwanda. Health Policy Plan. 2017; 32(7):1015-31. https://doi.org/10.1093/heapol/czx037.

54. Bharmal N, Derose KP, Felician M, Weden MM. Understanding the upstream social determinants of health. California: RAND; 2015.

55. Yip W, Fu H, Chen AT, Zhai T, Jian W, Xu R, et al. 10 years of health-care reform in China: progress and gaps in Universal Health Coverage. Lancet. 2019;394(10204):1192-204. https://doi.org/10.1016/S0140-6736(19)32136-1.

56. Jackson EF, Siddiqui A, Gutierrez H, Kante AM, Austin J, Phillips JF. Estimation of indices of health service readiness with a principal component analysis of the Tanzania Service Provision Assessment Survey. BMC Health Serv Res. 2015;15(1):536. https://doi.org/10.1186/s12913-015-12 03-7.

57. Vyas S, Kumaranayake L. Constructing socio-economic status indices: how to use principal components analysis. Health Policy Plan. 2006;21(6):459-68. https://doi.org/10.1093/heapol/czl029.

58. Wilhelm D, Lohmann J, De Allegri M, Chinkhumba J, Muula AS, Brenner S. Quality of maternal obstetric and neonatal care in low-income countries: development of a composite index. BMC Med Res Methodol. 2019;19(1):154. https://doi.org/10.1186/s12874-019-0790-0

59. MoHP [Nepal]: National Medical Standard for Maternal and Newborn Care. Vol. III. Kathmandu: Family Welfare Division, Department of Health Services 2020. Available from National Medical Standard for Maternal and Newborn Care Volume III (publichealthupdate.com)

60. Akinwande MO, Dikko HG, Samson A. Variance Inflation Factor: As a Condition for the Inclusion of Suppressor Variable(s) in Regression Analysis. Open J Stat. 2015;05(07):754-67. https://doi.org/10.4236/ojs.2015.57075.

61. Heinze G, Wallisch C, Dunkler D. Variable selection - A review and recommendations for the practicing statistician. Biom J. 2018;60(3):431-49. https://doi.org/10.1002/bimj.201700067.

62. Dunkler D, Plischke M, Leffondré K, Heinze G. Augmented backward elimination: a pragmatic and purposeful way to develop statistical models. PLoS One. 2014;9(11):e113677. https://doi.org/10.1371/journal.pone.0113677.

63. Singh DR, Sunuwar DR, Shah SK, Karki K, Sah LK, Adhikari B, et al. Impact of COVID-19 on health services utilization in Province-2 of Nepal: a qualitative study among community members and stakeholders. BMC Health Serv Res. 2021;21(1):174. https://doi.org/10.1186/s12913-021-06176-y.

64. Dhungel S. Provincial Comparison of Development Status in Nepal: An Analysis of Human Development Trend for 1996 to 2026. J Manag Dev Stud. 2018;28:53-68. https://doi.org/10.3126/jmds.v28i0.24958.

65. Goyet S, Rajbhandari S, Alvarez VB, Bayou A, Khanal S, Pokhrel TN. On-site clinical mentoring as a maternal and new-born care quality improvement method: evidence from a nurse cohort study in Nepal. BMC Nurs. 2020; 19(1):3. https://doi.org/10.1186/s12912-019-0396-1.

66. Adhikari RP, Shrestha ML, Satinsky EN, Upadhaya N. Trends in and determinants of visiting private health facilities for maternal and child health care in Nepal: comparison of three Nepal demographic health surveys, 2006, 2011, and 2016. BMC Pregnancy Childbirth. 2021;21(1):1. https://doi.org/10.1186/s12884-020-03485-8.

67. Maru D, Uprety S. The High Costs of Nepal's Fee-For-Service Approach To Health Care'. Health Affairs Blog. 2015;20. [cited03/04/2021]. Available from https://www.healthaffairs.org/do/10.1377/hblog20150720.049382/full.

68. Nepal A, Dangol SK, van der Kwaak A. Improving maternal health services through social accountability interventions in Nepal: an analytical review of existing literature. Public Health Rev. 2020;41:31. https://doi.org/10.1186/s4 0985-020-00147-0.

69. Karkee R, Tumbahangphe KM, Maharjan N, Budhathoki B, Manandhar D. Who are dying and why? A case series study of maternal deaths in Nepal.
BMJ Open. 2021;11(5):e042840. https://doi.org/10.1136/bmjopen-2020-04284

70. Karkee R, Tumbahanghe KM, Morgan A, Maharjan N, Budhathoki B, Manandhar DS. Policies and actions to reduce maternal mortality in Nepal: perspectives of key informants. Sex Reprod Health Matters. 2022;29(2): 1907026. https://doi.org/10.1080/26410397.2021.1907026.

71. Onta S, Choulagai B, Shrestha B, Subedi N, Bhandari GP, Krettek A Perceptions of users and providers on barriers to utilizing skilled birth care in mid- and far-western Nepal: a qualitative study. Glob Health Action. 2014; 7(1):24580. https://doi.org/10.3402/gha.v7.24580.

72. Mian NU, Alvi MA, Malik MZ, Iqbal S, Zakar R, Zakar MZ, et al. Approaches towards improving the quality of maternal and newborn health services in South Asia: challenges and opportunities for healthcare systems. Glob Health. 2018;14(1):17. https://doi.org/10.1186/s12992-018-0338-9.

73. Wilson AN, Spotswood N, Hayman GS, Vogel JP, Narasia J, Elijah A, et al. Improving the quality of maternal and newborn care in the Pacific region: A scoping review. Lancet Reg Health West Pac. 2020;3:100028. https://doi. org/10.1016/j.lanwpc.2020.100028.

74. Bradley S, Kamwendo F, Masanja H, de Pinho H, Waxman R, Boostrom C, et al. District health managers' perceptions of supervision in Malawi and Tanzania. Hum Resour Health. 2013;11(1):43. https://doi.org/10.1186/1478-44 91-11-43.

75. Jahangir YT, Shrestha A, Alhaan F, Meyer SB. Service user and healthcare provider perspectives on barriers for men using sexually transmitted infection services in public hospital of Nepal: a qualitative study. J Commun Healthc. 2020;13(4):314-24. https://doi.org/10.1080/17538068.2020.1788373.

76. Wasti SP, Randall J, Simkhada P, Van Teijlingen E. In what way do Nepalese cultural factors affect adherence to antiretroviral treatment in Nepal? Health Sci J. 2011;5(1):37-47.

77. Bolan N, Cowgill KD, Walker K, Kak L, Shaver T, Moxon S, et al. Human Resources for Health-Related Challenges to Ensuring Quality Newborn Care in Low- and Middle-Income Countries: A Scoping Review. Glob Health Sci Pract. 2021:9(1):160

\section{Publisher's Note}

Springer Nature remains neutral with regard to jurisdictional claims in published maps and institutional affiliations.

\section{Ready to submit your research? Choose BMC and benefit from:}

- fast, convenient online submission

- thorough peer review by experienced researchers in your field

- rapid publication on acceptance

- support for research data, including large and complex data types

- gold Open Access which fosters wider collaboration and increased citations

- maximum visibility for your research: over $100 \mathrm{M}$ website views per year

At $\mathrm{BMC}$, research is always in progress.

Learn more biomedcentral.com/submissions 